\title{
ENDEMIC SYPHILIS
}

Whether the extra-venereal treponematoses are regarded as one disease or as several different diseases, they may be grouped into three more or less distinct clinical entities : yaws, pinta, and endemic syphilis. The sibbens of Scotland, the radesyge of Norway, and the complaint which ravaged the Indians in the neighbourhood of St. Paul's Bay during the early settlement of Canada, are historical examples of endemic syphilis (Lancereaux, 1868-9). At the present time, endemic syphilis is found in various areas ; it includes the skerlievo of the Balkans, the bejel of Iraq, the njovera of Southern Rhodesia (Willcox, 1951), a similar condition in adjacent Bechuanaland (Murray and others, 1952), and a small focus near Madras, India (Rajam and Rangiah, 1952).

The endemic syphilis of the Balkans is said to have arisen from infection introduced and maintained by the periodic incursions of the Ottoman armies. Although widespread at one time, it is now more or less localized to Bosnia and Herzegovina, where, in an epidemiological setting similar to that of Cromwellian England, it affords excellent opportunities for a study of 'primitive' syphilis. Records for 37 districts from 1905 to 1911 revealed 41,398 cases and an infection rate of 8.3 per cent. of the population examined. After the collapse of the Austro-Hungarian Empire, an attempt was made to begin control measures, and in the period 1926-1933 some 57,965 cases of syphilis were found with an infection rate of 11.8 per cent. amongst those examined. Further control plans, formulated in 1941, were frustrated by the German occupation. Since 1948, however, the Yugoslav health administration has developed a nation-wide syphilis control programme as part of its general health activities, since the introduction of penicillin was thought to make possible a comprehensive attack on the problem of endemic syphilis. The World Health Organization and the United Nations International Childrens' Emergency Fund have assisted the national authorities, and by the end of 1952 some $1,472,402$ persons had been examined, of whom 90,235 were treated with penicillin. This massive attack on endemic syphilis in Yugoslavia is described by Grin (1952).

The Balkan disease, as a rule, has a non-venereal transmission. It affects both sexes equally and all ages, but is most frequently acquired in childhood. Essentially a family disease, it is prevalent in rural districts where social and economic conditions are poor. Frequently an infectious mucous patch in the mouth of a secondary type is the first sign of the disease to be encountered. Grin observes that its geographical distribution is patchy, but is unable to explain why this is so. In areas where the disease is spreading the percentage of infected children is high, and in areas where it is receding the incidence of childhood infections is low. The general absence of the primary sore is a feature of endemic syphilis everywhere, and is probably related to the size of the inoculum. When this is massive, a primary sore will arise. A not uncommon example of this is the throwback infection, or Grin's ' transpositional' lesion, on the nipple of a mother infected by her own child.

$\mathrm{He}$ refutes any suggestion that this is a 'benign' disease, and justly points out that destructive gummatous, facial, or neurological involvement have greater pyschological and economic effects upon persons with high living standards than amongst those with a low standard. As living standards rise the condition loses its 'benign' nature without changing its actual character, and it is unnecessary to theorize on the posstbility of different strains of treponemes. The fact that the disease was once thought to be benign resulted in the feeling that it was a different condition from venereal syphilis. Grin emphasizes that this is not so, and endeavours to explain a number of the alleged peculiarities of endemic syphilis. The late gummatous lesions do not differ essentially from those of venereal syphilis, although they may be more common and are sometimes made more obvious through neglect. Of particular interest is the observation that all forms of neurosyphilis are encountered in the Balkan treponematosis, although this had previously been stated not to be the case. At the present time neurological involvement is stated to be very rare or absent in bejel, and one wonders whether here also the fullness of time may bring a change of opinion. Similarly, it is stated that cardiovascular syphilis is well-known in the endemic areas in Yugoslavia, although there are no accurate figures as to its incidence.

One of the most stimulating sections of the Monograph is that which deals with the incidence of tertiary lesions. Grin observes that in areas where the incidence of early infections is high, so also is that of gummatous lesions. Indeed he suggests that the incidence of tertiary lesions may be used as an epidemiological index. To explain this he reintroduces the theory of superinfection. Gummata occur as a result of allergy in a previously sensitized host, and if a person previously sensitized 
is superinfected, he develops lesions related clinically to the time since the acquisition of the first infection. Thus the children with fresh disease may superinfect parents who have had it before and were untreated or inadequately treated. The parents then develop gummata.

The theory is no new one. It was well-known to Jonathan Hutchinson and the master French syphilographers. It has also been appreciated by those who practise tropical medicine, for observations have been made on yaws concerning the 'transpositional' lesions of mothers who have previously had the disease. Gummatous-looking ulcers develop on the breasts of these cases, and no $T$. pallida are found in them. Venereologists in the United Kingdom will recall, when syphilis was at its peak 5 or 6 years ago, the occasional case of extensive penile ulceration encountered in patients with strongly positive serum tests, but in whom no $T$. pallida could be demonstrated under the darkfield. It is possible that these were examples of this phenomenon.

Grin notes also that as the endemic dies down so does the incidence of tertiary lesions, and he suggests that this is so because the chances of superinfection are diminished. This observation may have application in Great Britain, where it has been suggested that many cases of early syphilis must have escaped detection when the disease was prevalent immediately after the war, and that they may cause a commensurate rise in the numbers of cases of manifest late syphilis in the future. If the theory is correct this rise should not include gummatous syphilis, for by now the chances of reinfection in Britain are drastically reduced. Whether the incidence of cardiovascular and neurosyphilis increases is a matter of considerable speculative interest for it would help to show whether these more malignant late manifestations have a trigger of origin similar to or different from that of gummata.

The alleged absence of congenital transmission was at one time said to be a characteristic of endemic syphilis. Grin considered that this observation is largely accounted for by the age at which the disease is usually acquired, but that if a woman contracts the disease reasonably near to the childbearing age then congenital transmission may occur. Furthermore, under primitive conditions, and amid the grim business of survival of the fittest in an environment of dysentery and malaria, the syphilitic infant is the first to die and is therefore seldom seen by the visiting observer.

The field teams in Yugoslavia have used procaine penicillin with aluminium monostearate, at first with 3.6 to 4.2 mega units given as six or seven injections of PAM every second day, and latterly with fewer doses including single injections of 1.5 and 3.2 mega units. The clinical and serological results are deemed satisfactory.

Certain epidemiological observations of great importance have emerged and these are graphically illustrated by charts and family histories. Thus it is necessary to examine as near to 100 per cent. of the population as possible, and to treat not only those patients who are obviously infected but all the household contacts as well. This procedure will take care of those patients who are incubating the disease, and, when no serum tests are being performed to detect them, most of the infectious latent cases as well. The return of the team to the area after about 6 months is essential to ensure that the endemic is not once again developing from a small, previously undetected residue, from treatment failures, or from re-introduction of the disease from outside. On this return visit, the whole population, and not only those originally treated, must once again be examined, and the contacts of infected cases treated. The experience in Yugoslavia suggests that by this means it is possible to eradicate any infectious ' reservoir' by mass treatment, and that " the epidemiological situation cannot conceivably return to its original form after one or more followup examinations have been made". However, some permanent machinery is required to deal with sporadic cases during the ultimate ' consolidation phase' of the programme.

Dr. Grin is to be congratulated on his Monograph. It is of the stature of that of Bruusgaard which, with all its limitations, has formed part of the basic structure of our knowledge of syphilis unfettered by treatment. It not only adds to these foundations, but creates a base-line of modern epidemiological experience.

The monograph also includes a contribution by Dr. E. Gurney Clark who has visited Yugoslavia and has studied the project in detail. He adds to the historical and epidemiological perspective, and sums up his highly favourable impressions by saying "I have never seen public health funds spent to greater advantage".

\section{REFERENCES}

Lancereaux, E. (1868-9). “A Treatise on Syphilis”, trans. G. Whitley. New Sydenham Society, London.

Willcox, R. R. (1951). S. Afr. med. J., 25, 501.

Murray, J. F., Merriweather, A. M., Keen, P., and Sachs, S. B. (1952). Med. ill., Lond., 6, 407.

Grin, E. I. (1952). "Studies in Treponematosis", Bull. World Hlth. Org., 7, 1-74, and (1953). WHO Monograph Series, Geneva.

Rajam, R. V., and Rangiah, P. N. (1952). WHO/VD/79 (unpublished). 